\title{
Genetic effect of an InDel in the promoter region of the NUDT15 and its effect on myoblast proliferation in chickens
}

\author{
Chengjie Wei ${ }^{1,2+}$, Yufang Niu ${ }^{1,2 \dagger}{ }^{2}$, Bingjie Chen ${ }^{1,2}$, Panpan Qin ${ }^{1,2}$, Yanxing Wang ${ }^{1,2}$, Dan Hou ${ }^{1,2}$, Tong Li ${ }^{1,2}$, \\ Ruiting $\mathrm{Li}^{1,2}$, Chunxiu Wang ${ }^{1,2}$, Huadong Yin ${ }^{3}$, Ruili Han ${ }^{1,2}$, Huifen $\mathrm{Xu}^{1,2}$, Yadong Tian ${ }^{1,2}$, Xiaojun Liu ${ }^{1,2}$, \\ Xiangtao Kang ${ }^{1,2}$ and Zhuanjian $\mathrm{Li}^{1,2^{*}}$
}

\begin{abstract}
Background: Molecular breeding accelerates the speed of animal breeding. Screening molecular markers that can affect economic traits through genome-wide association studies (GWAS) can provide a theoretical basis for molecular breeding. At present, a large number of molecular markers have been screened in poultry research, but few reports on how molecular markers affect economic traits exist. It is particularly important to reveal the action mechanisms of molecular markers, which can provide more accurate information for molecular breeding.

Results: The aim of this study was to investigate the relationships between two indels (NUDT15-indel-2777 and NUDT15-indel-1673) in the promoter region of NUDT15 and growth and carcass traits in chickens and to explore the regulatory mechanism of NUDT15. Significant differences were found in genotype and allele frequencies among commercial broilers, commercial laying hens and dual-purpose chickens. The results of association analyses showed that these two indel loci could significantly affect growth traits, such as body weight, and carcass traits. Tissue expression profiling at E12 showed that the expression of NUDT15 was significantly higher in skeletal muscle, and time-expression profiling of leg muscle showed that the expression of NUDT15 in myoblasts was significantly higher in the E10 and E12 proliferation stages than in other stages. Promoter activity analysis showed that pro-1673-I and pro-1673-D significantly inhibited promoter activity, and the promoter activity of pro-1673-D was significantly lower than that of pro-1673-I. In addition, when NUDT15 was overexpressed or underwent interference in chicken primary myoblasts (CPMs), NUDT15 could inhibit the proliferation of CPMs.
\end{abstract}

Conclusion: The results suggest that the studied indels in the promoter region of NUDT15 may regulate the proliferation of CPMs by affecting NUDT15 expression, ultimately affecting the growth and carcass traits of chickens. These indel polymorphisms may be used together as molecular markers for improving economic traits in chickens.

Keywords: NUDT15, Indel, Promoter, Muscle, Primary myoblast, Cell proliferation

*Correspondence: lizhuanjian@163.com

${ }^{\dagger}$ Chengjie Wei and Yufang Niu contributed equally to this work.

${ }^{2}$ Henan Key laboratory for innovation and utilization of chicken germplasm resources, Zhengzhou 450046, China

Full list of author information is available at the end of the article

\section{Background}

Studies of the molecular mechanisms of monogenic traits are widely pursued in the molecular breeding of animals and plants due to the unique genotype-phenotype associations of these traits $[1,2]$. Many recent studies in chickens have shown that there is a major quantitative trait locus (QTL) at the end of chromosome 1 (Chr1) 
$[3,4]$. This QTL contributes $14.4 \%$ of the genetic variation in growth [5], and it has been proven to be significantly linked to growth-related traits such as body and muscle weights [6-9]. Multiple candidate genes exist in this QTL, including MLNR [10], retinoblastoma 1 (RB1) [11], and forkhead box O1 (FOXO1) [12]. Chicken nudix hydrolase 15 (NUDT15, 168,554,754-168,558,378) is also located in the growth QTL on Chr1. However, the currently reported candidate genes cannot fully explain the genetic variation in growth contributed by this QTL interval.

Multiallelic sites are produced by a high frequency of gene mutations, and gene mutations are a key factor in the formation of genetic diversity [13]. Within species, genetic diversity underlies species diversity [14]. In addition, correctly accounting for multiallelic sites is important both for the understanding of genetic structures in populations and for the more pragmatic purpose of searching for 'causative' disease alleles in individuals and cohorts [15]. The study of multiallelic genes is conducive to the maintenance of biodiversity, and identifying dominant multialleles will help accelerate the cultivation of excellent breeds and the determination of therapeutic targets for many diseases.

NUDT15 is a nucleotide triphosphate diphosphatase that consists of 164 amino acids with a nudix hydrolase domain featuring a conserved nudix box that coordinates catalytic $\mathrm{Mg}^{2+}$ [16]. NUDT15 is mainly involved in the metabolism of thiopurine, preventing the integration of damaged thiopurine into DNA, repairing DNA mismatches, maintaining steady-state DNA replication, and participating in multiple cell metabolism pathways $[17,18]$. Current research on NUDT15 is mainly focused on the effects of mutations in human NUDT15 on the metabolism of purine drugs, which are widely used in the treatment of leukemia and autoimmune diseases [19-21]. NUDT15 (also known as MYH2) can regulate the replication of DNA by affecting the metabolism of thiopurine, and a decrease in its expression can inhibit the proliferation of NB4 and HL-60 cells [22]. The development of a chemical probe against NUDT15 facilitated the discovery that it can promote cell proliferation by forming a complex with proliferating cell nuclear antigen (PCNA) and inhibiting the degradation of PCNA [23]. Proliferating cell nuclear antigen is protected from degradation by forming a complex with MutT homolog2. However, there has been little research and reporting on NUDT15 in chickens.

Promoters are DNA sequences that regulate gene expression by recognizing and binding to regulatory elements such as transcription factors and enhancers [24, 25]. In recent years, gene transcriptional regulation by promoters in livestock and poultry has been widely studied in the context of disease treatment, species evolution and developmental regulation [26, 27]. Many studies have shown that mutations in the promoter region can play a key role in regulating growth and carcass traits [28-30] and hence can have important impacts on the economic traits of livestock and poultry. Screening for mutations related to development, especially causal mutations, will help accelerate livestock and poultry breeding processes.

This study aimed to explore the effects of indels in the promoter region of NUDT15 on the growth and carcass traits of the $F_{2}$ resource group and on the proliferation of chicken primary myoblasts (CPMs). We found that NUDT15 is located within a QTL on Chr1 that is significantly related to chicken growth and development. We experimentally determined the differences in $F_{2}$ resource group growth and carcass traits between chickens with different genotypes of the NUDT15 promoterregion, NUDT15-indel-2777 and NUDT15-indel-1673, and performed gene overexpression and interference experiments to explore the function of NUDT15 in CPMs. We found that the NUDT15-indel-2777 and NUDT15-indel-1673 genotypes were significantly related to multiple growth and carcass traits. In particular, NUDT15-indel-2777 can regulate the transcriptional activity and gene expression of NUDT15 and thus regulate the proliferation of CPMs. This study aimed to explore the role of NUDT15 in chicken growth and development and to provide useful information for chicken molecular breeding.

\section{Results \\ Genotyping and sequencing confirmation}

In this study, the insertion region was sequenced to determine the nature of insertions/deletions. According to the sequencing results, we identified two 23-bp indel mutations in the promoter region of NUDT15, which were located $2777 \mathrm{bp}$ and $1673 \mathrm{bp}$ from the ATG and thus named NUDT15-indel-2777 and NUDT15-indel-1673 (Fig. 1). According to the

$$
\begin{gathered}
\text { NUDT15-2777-indel } \\
\downarrow
\end{gathered}
$$$$
\text { NUDT15-1673-indel }
$$

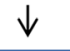

$\operatorname{ATG}(+1)$

Fig. 1 The relative position of two mutation sites. The two indel mutations of $23 \mathrm{bp}$ in the promoter region of the NUDT15 gene, which were located $2777 \mathrm{bp}$ and $1673 \mathrm{bp}$ from the ATG and thus named NUDT15-indel-2777 and NUDT15-indel-1673 
electrophoresis results, there were two genotypes of NUDT15-indel-2777 (Fig. 2a, b), which were named $\mathrm{N}^{1}$ (113bp) and $\mathrm{N}^{2}$ (113bp/90bp), and three genotypes of NUDT15-indel-1673 (Fig. 2c, d; the full-length gels are included in S1 and S2), which were named $\mathrm{N}^{3}$ (150 bp), $\mathrm{N}^{4}(127 \mathrm{bp})$ and $\mathrm{N}^{5}(150 \mathrm{bp} / 127 \mathrm{bp})$.

\section{Relative expression of NUDT15 in different genotypes and spatiotemporal expression of NUDT15}

The expression of chicken NUDT15 was detected by quantitative polymerase chain reaction (qPCR) in different tissues and at different developmental stages in AA broilers and LS chickens. The expression of NUDT15 in the leg and breast muscles was significantly higher than that in other tissues in E12-stage AA broilers (Fig. 3a), but the expression in skeletal muscle was significantly lower than that in the pancreas and liver in chicks at $2 \mathrm{w}$ (Fig. 3b). The NUDT15 expression levels in the chest and leg muscles of AA and LS chickens were significantly higher in E10 and E12 than in other periods (Fig. 3c, d). Relative expression analysis in leg muscle isolated from animals with different genotypes showed that NUDT15 expression was not significantly different between the $\mathrm{N}^{1}$ and $\mathrm{N}^{2}$ genotypes, whereas NUDT15 was expressed at lower levels in $\mathrm{N}^{4}$ than in $\mathrm{N}^{3}$ and $\mathrm{N}^{5}$ (Fig. 3e, $\left.\mathrm{f}\right)(P<0.05)$.

\section{Genotypic and allelic frequencies of NUDT15-indel-2777} and NUDT15-indel-1673 among the $F_{2}$ resource population and different breeds

We calculated the genotypic and allelic frequencies of NUDT15-indel-2777 and NUDT15-indel-1673 in different breeds (Table 1). In the 10 examined breeds, excluding HBD and AA, the allelic frequencies of 2777-I $\left(\mathrm{F}_{2}\right.$ population: $44 \%$, XC: $50 \%$, GF: $50 \%$, CF: $50 \%$, LS: $45 \%$, CS: $46 \%$, GS: $43 \%$, and HL: $43 \%)$ and $1673-\mathrm{I}\left(\mathrm{F}_{2}\right.$ population: $29 \%$, XC: $37 \%$, GF: $27 \%$, CF: 37\%, LS: $37 \%$, CS: $37 \%$, GS: $33 \%$, and HL: $29 \%$ ) were significantly higher than those of 2777-D and 1673-D. The allelic frequencies of 2777-I and 1673-D in commercial broilers (HBD: 36\% (2777-I), 38\% (1673-D); AA: 37\% (2777-I), 36\% (1673D)) were significantly higher than those in dual-purpose chickens and commercial laying hens. In addition, we observed different genotypic frequencies in dual-purpose chickens, commercial laying hens and commercial broilers. $\mathrm{N}^{1} \mathrm{~N}^{3}$ was significantly more common than other genotypes in dual-purpose chickens and commercial laying hens, while $\mathrm{N}^{2} \mathrm{~N}^{3}$ and $\mathrm{N}^{2} \mathrm{~N}^{4}$ were the least frequent genotypes, and only three genotypes $\left(\mathrm{N}^{1} \mathrm{~N}^{3}\right.$, a

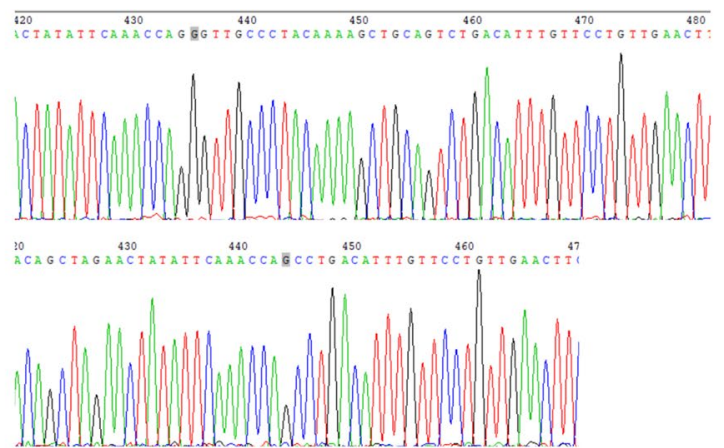

b

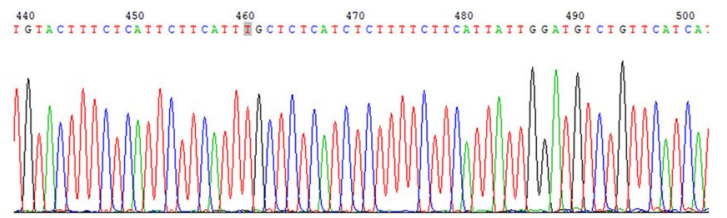

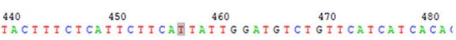

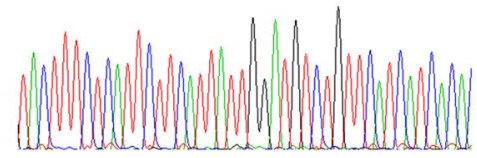

c

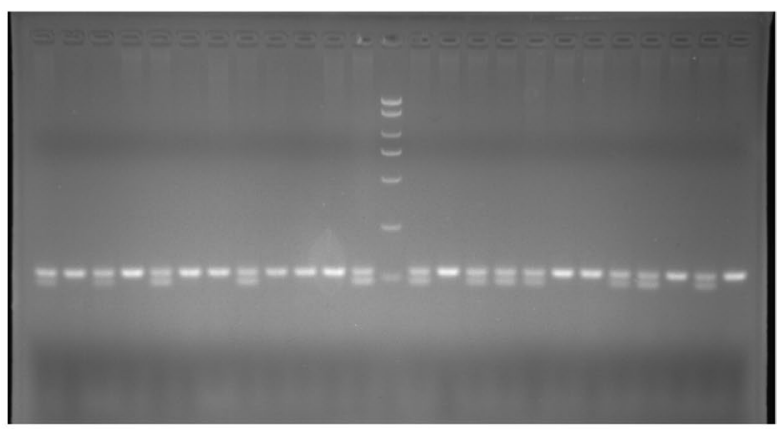

d

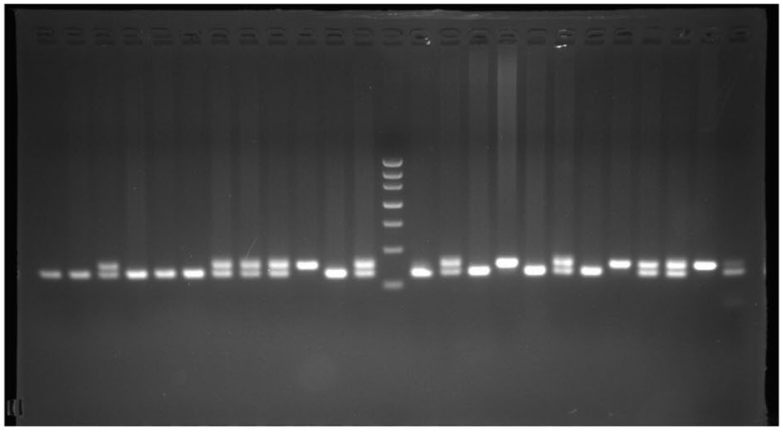

Fig. 2 Sequencing comparison of two novel 23-bp indel mutations polymorphism of promoter region within the chicken NUDT15 gene and electrophoresis pattern. a NUDT15-2777-indel sequencing comparison. b NUDT15-1673-indel sequencing comparison. $\mathbf{c}$ Electrophoresis pattern of the NUDT15-2777-indel. d Electrophoresis pattern of the NUDT15-1673-indel 


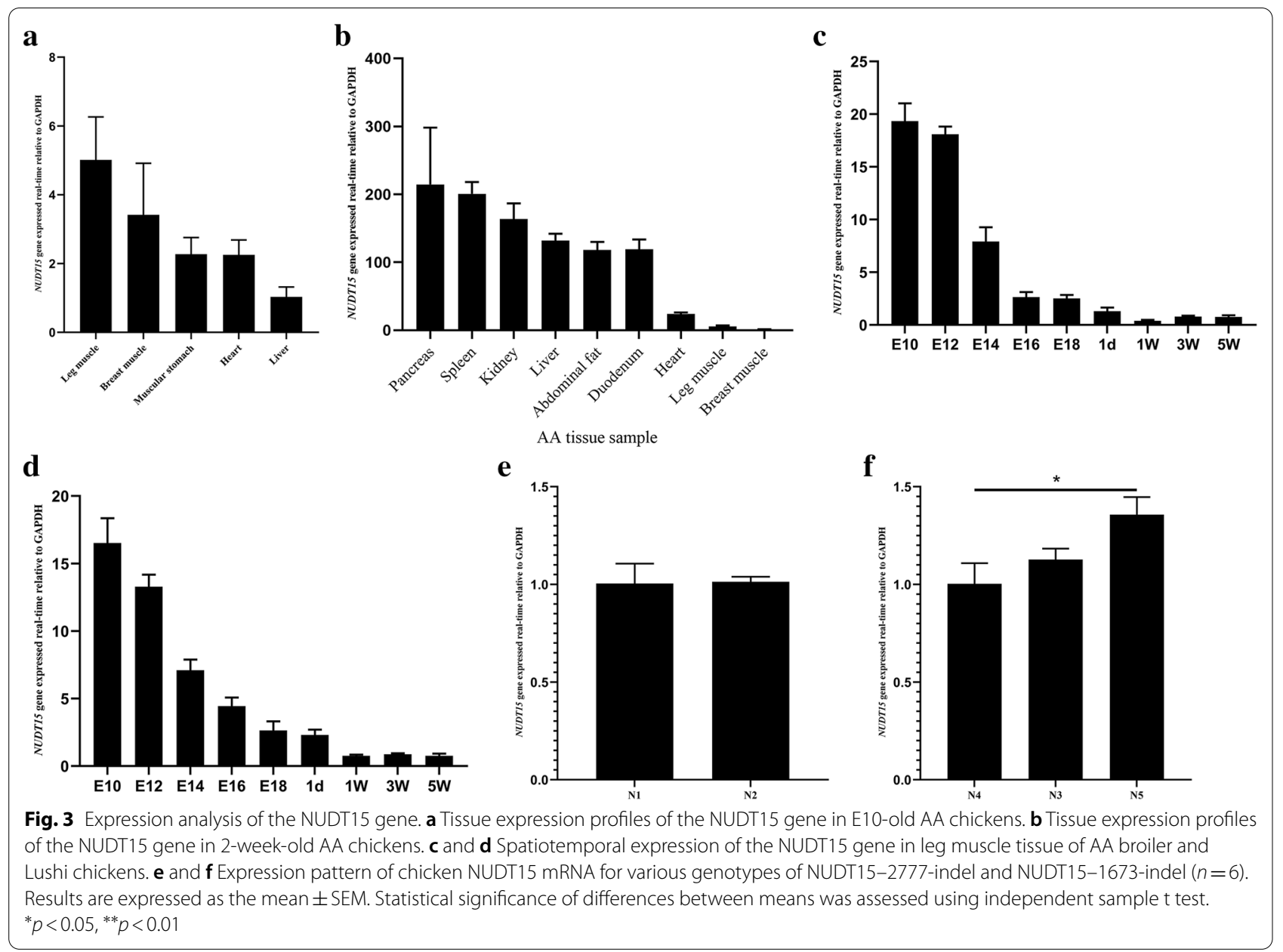

$\mathrm{N}^{1} \mathrm{~N}^{4}$ and $\mathrm{N}^{1} \mathrm{~N}^{5}$ ) were observed in $\mathrm{XC}, \mathrm{GF}$, and CF. Among commercial broilers, $\mathrm{N}^{2} \mathrm{~N}^{4}$ was the predominant genotype. In addition, the frequencies of the $\mathrm{N}^{2} \mathrm{~N}^{4}$ and $\mathrm{N}^{2} \mathrm{~N}^{5}$ genotypes were significantly higher in commercial broilers than in dual-purpose chickens and commercial laying hens (Table 1). The distributions of different genotypes in different populations are more intuitively displayed in Fig. 4a.

\section{Associations of the multiallelic indel in the NUDT15 gene with carcass traits}

NUDT15-indel-2777 and NUDT15-indel-1673 had a significant effect on SEW, EW, EWR, HW, CLW, DWW, PW, BMW, LeW, LMW, BMWR and CW $(P<0.01)$. Among these traits, EWR was extremely positively correlated with the multiallelic indel $(P<0.05)$. In addition, the results showed that the $\mathrm{N}^{2} \mathrm{~N}^{4}$ genotype produced the largest carcass traits, followed by $\mathrm{N}^{2} \mathrm{~N}^{5}, \mathrm{~N}^{1} \mathrm{~N}^{3}, \mathrm{~N}^{1} \mathrm{~N}^{4}$ and $\mathrm{N}^{1} \mathrm{~N}^{5}$, whereas the $\mathrm{N}^{2} \mathrm{~N}^{3}$ genotype produced the least desirable carcass traits (Table 2).

\section{Associations of the multiallelic indel in NUDT15 with growth traits}

NUDT15-indel-2777 and NUDT15-indel-1673 had significant effects on body weight (BW) at $2 \mathrm{w}, 4 \mathrm{w}, 6 \mathrm{w}, 8$ $\mathrm{w}, 10 \mathrm{w}$, and $12 \mathrm{w}$ (Fig. $4 \mathrm{~b})$; PW at $4 \mathrm{w}$ and $8 \mathrm{w}(P<0.05)$; shank circumference, sternal length, and body length at $4 \mathrm{w}, 8 \mathrm{w}$, and $12 \mathrm{w}$; and chest breadth at $12 \mathrm{w}(P<0.01)$. In addition, the results showed that the $\mathrm{N}^{2} \mathrm{~N}^{4}$ genotype produced the most desirable growth traits, followed by $\mathrm{N}^{2} \mathrm{~N}^{5}, \mathrm{~N}^{1} \mathrm{~N}^{3}, \mathrm{~N}^{1} \mathrm{~N}^{4}$ and $\mathrm{N}^{1} \mathrm{~N}^{5}$, and the $\mathrm{N}^{2} \mathrm{~N}^{3}$ genotype produced the least desirable growth traits (Table 3 ).

\section{Promoter activity of NUDT15}

For NUDT15-indel-2777 and NUDT15-indel-1673, mutant-type (I) and wild-type (D) PGL4.10 vectors were constructed and named Pro-2777-I, Pro-2777-D, Pro-1673-I, and Pro-1673-D. Fluorescence activity measurements of Pro-2777-I and Pro-2777-D showed that the activities of Pro-2777-I and Pro-2777-D were significantly higher than that of pGL4.10. Moreover, the promoter activity of Pro-2777-I was higher than that 
Table 1 Genotypic and allelic frequencies and related genetic parameters for the chicken NUDT15 gene

\begin{tabular}{|c|c|c|c|c|c|c|c|c|c|c|c|}
\hline \multirow[t]{2}{*}{ Breeds/n } & & \multicolumn{6}{|c|}{ Genotypic distribution } & \multicolumn{4}{|c|}{ Allelic frequencies } \\
\hline & & $N^{1} N^{3}$ & $N^{1} N^{4}$ & $N^{1} N^{5}$ & $N^{2} N^{3}$ & $\mathrm{~N}^{2} \mathrm{~N}^{4}$ & $\mathrm{~N}^{2} \mathrm{~N}^{5}$ & I-2777 & 2777-D & I673-I & 1673-D \\
\hline${ }^{1} \mathrm{~F} 2$ & $\mathrm{~F} 2 / 790$ & 0.37 & 0.17 & 0.22 & 0.04 & 0.08 & 0.12 & 0.44 & 0.06 & 0.29 & 0.21 \\
\hline \multirow[t]{6}{*}{ Dual-purpose chickens } & XC/308 & 0.69 & 0.21 & 0.10 & 0.00 & 0.00 & 0.00 & 0.50 & 0.00 & 0.37 & 0.13 \\
\hline & GF/176 & 0.43 & 0.36 & 0.22 & 0.00 & 0.00 & 0.00 & 0.50 & 0.00 & 0.27 & 0.23 \\
\hline & $\mathrm{CF} / 87$ & 0.60 & 0.13 & 0.28 & 0.00 & 0.00 & 0.00 & 0.50 & 0.00 & 0.37 & 0.13 \\
\hline & LS/182 & 0.64 & 0.12 & 0.05 & 0.02 & 0.08 & 0.09 & 0.45 & 0.05 & 0.37 & 0.13 \\
\hline & $\mathrm{CS} / 92$ & 0.58 & 0.09 & 0.15 & 0.02 & 0.04 & 0.13 & 0.46 & 0.04 & 0.37 & 0.13 \\
\hline & GS/143 & 0.48 & 0.14 & 0.10 & 0.03 & 0.07 & 0.19 & 0.43 & 0.07 & 0.33 & 0.17 \\
\hline Commercial laying hens & HL/222 & 0.35 & 0.15 & 0.24 & 0.01 & 0.04 & 0.21 & 0.43 & 0.07 & 0.29 & 0.21 \\
\hline \multirow[t]{2}{*}{ Commercial broilers } & $\mathrm{HBD} / 236$ & 0.05 & 0.24 & 0.14 & 0.03 & 0.33 & 0.22 & 0.36 & 0.14 & 0.12 & 0.38 \\
\hline & AA/309 & 0.09 & 0.24 & 0.13 & 0.04 & 0.32 & 0.17 & 0.37 & 0.13 & 0.14 & 0.36 \\
\hline
\end{tabular}

Note: $F_{2}{ }^{1} F_{2}$ resource population, XC Xichuan black-boned chicken, GF Guifei chicken, CF Cockfighting, LS Lushi green-eggshell chicken, CS Changshun green-eggshell chicken, GS Gushi chicken, HL Hy-Line variety brown chicken, HBD Hubbard broiler chicken, $A A$ Arbor Aceres

of Pro-2777-D, but the difference was not significant. Fluorescence activity measurements of Pro-1673-I and Pro-1673-D showed that the activities of Pro-1673-I and Pro-1673-D were significantly lower than that of pGL4.10. Additionally, the promoter activity of Pro1673-I was significantly higher than that of Pro-1673-D (Fig. 5).

\section{NUDT15 inhibited CPM proliferation}

To explore the effect of NUDT15 on CPMs, we transfected these cells with a NUDT15 overexpression vector or small interfering RNA (siRNA). The transfection efficiency was analyzed by qPCR, which showed that both the overexpression vector and siRNA significantly changed the expression of NUDT15 (Fig. 6a, b). The expression of cell cycle-promoting genes, including cyclin D1 (CCND1), cyclin B2 (CCNB2), and PCNA, was significantly decreased upon overexpression of NUDT15 (Fig. 6c). After NUDT15 siRNA interference, the expression of these genes increased significantly (Fig. 6d). Using 5-ethynyl-2'-deoxyuridine (EdU) and Cell Counting Kit-8 (CCK-8) assays (Fig. 6e, f, g, h, i, j), we found that NUDT15 overexpression inhibited the proliferation of CPMs. In addition, the overexpression of NUDT15 significantly increased the proportion of cells in G0/G1 phase and decreased the proportions of cells in $\mathrm{G} 2$ and $\mathrm{S}$ phases. The opposite result was observed after siRNA interference (Fig. 6k). These results suggest that NUDT15 can inhibit the proliferation of CPMs.
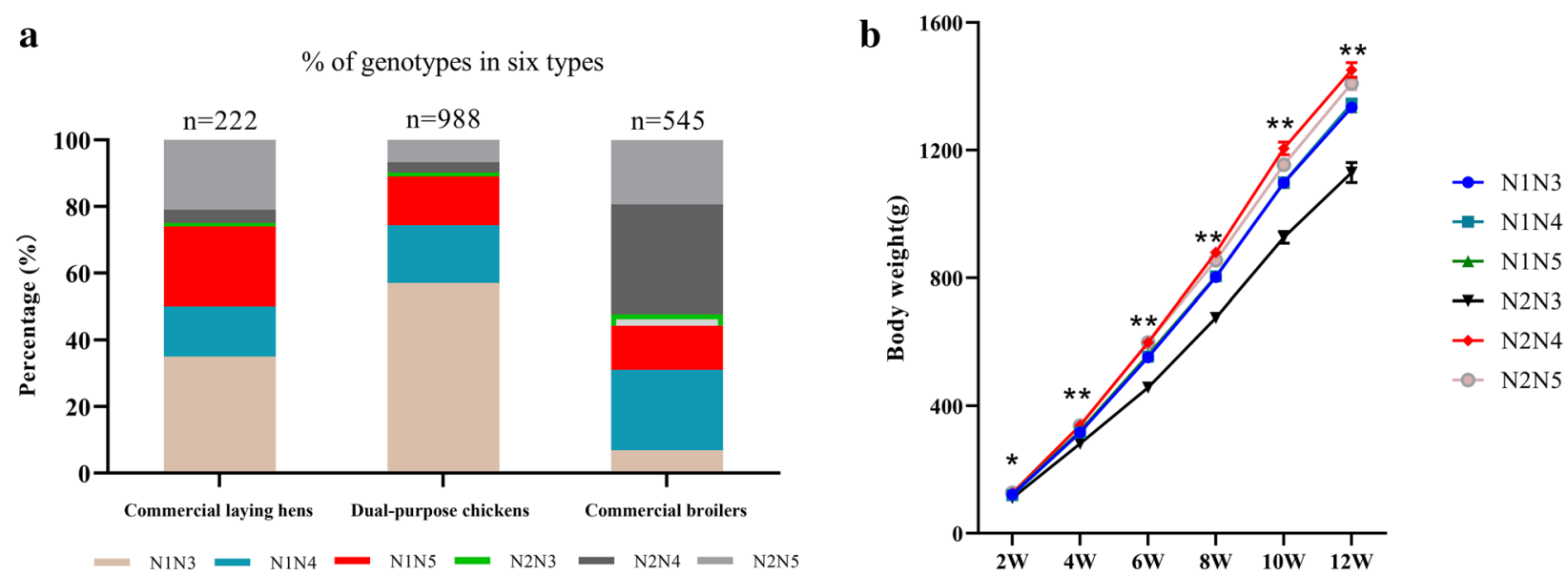

Fig. 4 Genotype percentage statistics and growth curves. a Percentage of different genotypes in different populations. Commercial laying hens (Hy-Line), dual-purpose type (Xichuan, Guifei, Game fowl, Lushi, Changshun, Gushi),commercial broiler (Hubbard, Arbor Aceres). b Developmental changes in body weight of different genotypes of NUDT15 in $F_{2}$ generation at different weeks. Results are expressed as the mean \pm SEM. Statistical significance of differences between means was assessed using independent sample t test. ${ }^{*} p<0.05,{ }^{* *} p<0.01$ 
Table 2 Associations of combination haplotype with growth traits in $F_{2}$ resource population

\begin{tabular}{|c|c|c|c|c|c|c|c|c|}
\hline \multirow{2}{*}{$\begin{array}{l}\text { Growth } \\
\text { Traits }\end{array}$} & \multirow{2}{*}{$\begin{array}{l}\text { Age, } \\
\text { week }\end{array}$} & \multicolumn{6}{|c|}{ Multiallelic genotypes (Mean $\pm \mathrm{SE}$ ) } & \multirow[t]{2}{*}{$P$-Value } \\
\hline & & $N^{1} N^{3}$ & $N^{1} N^{4}$ & $N^{1} N^{5}$ & $N^{2} N^{3}$ & $N^{2} N^{4}$ & $N^{2} N^{5}$ & \\
\hline \multirow{6}{*}{$\begin{array}{l}\text { Body } \\
\text { weight, g }\end{array}$} & 2 & $122.022 \pm 1.114$ & $119.72 \pm 1.684$ & $122.911 \pm 1.456$ & $110.818 \pm 1.985$ & $126.573 \pm 2.388$ & $127.118 \pm 1.994$ & 0.037 \\
\hline & 4 & $316.739 \pm 2.66$ & $316.133 \pm 3.97$ & $321.386 \pm 3.382$ & $281.323 \pm 3.9$ & $339.06 \pm 5.616$ & $337.809 \pm 4.844$ & 0.000 \\
\hline & 6 & $551.885 \pm 4.962$ & $554.329 \pm 7.521$ & $559.657 \pm 6.347$ & $457.169 \pm 5.907$ & $598.132 \pm 10.589$ & $598.615 \pm 8.903$ & 0.000 \\
\hline & 8 & $802.291 \pm 7.46$ & $804.802 \pm 11.14$ & $805.085 \pm 9.37$ & $675.268 \pm 8.418$ & $879.645 \pm 15.991$ & $855.072 \pm 13.312$ & 0.000 \\
\hline & 10 & $1098.281 \pm 9.142$ & $1099.133 \pm 13.513$ & $1096.967 \pm 11.8$ & $926.415 \pm 18.48$ & $1205.512 \pm 19.729$ & $1154.507 \pm 16.283$ & 0.000 \\
\hline & 12 & $1330.255 \pm 11.035$ & $1345.827 \pm 16.141$ & $1334.701 \pm 14.032$ & $1129.838 \pm 31.326$ & $1451.111 \pm 23.608$ & $1409.609 \pm 19.692$ & 0.000 \\
\hline \multirow{3}{*}{$\begin{array}{l}\text { shank } \\
\text { circumfer- } \\
\text { ence, cm }\end{array}$} & 4 & $2.671 \pm 0.011$ & $2.673 \pm 0.017$ & $2.691 \pm 0.014$ & $2.602 \pm 0.03$ & $2.777 \pm 0.024$ & $2.744 \pm 0.02$ & 0.000 \\
\hline & 8 & $3.384 \pm 0.013$ & $3.445 \pm 0.019$ & $3.412 \pm 0.016$ & $3.268 \pm 0.049$ & $3.517 \pm 0.029$ & $3.447 \pm 0.023$ & 0.000 \\
\hline & 12 & $3.798 \pm 0.014$ & $3.861 \pm 0.021$ & $3.853 \pm 0.018$ & $3.612 \pm 0.065$ & $3.937 \pm 0.03$ & $3.879 \pm 0.025$ & 0.000 \\
\hline $\begin{array}{l}\text { chest } \\
\text { breadth, } \\
\mathrm{cm}\end{array}$ & 12 & $6.305 \pm 0.036$ & $6.177 \pm 0.053$ & $6.346 \pm 0.046$ & $6.594 \pm 0.034$ & $6.581 \pm 0.078$ & $6.455 \pm 0.065$ & 0.000 \\
\hline \multirow{3}{*}{$\begin{array}{l}\text { sternal } \\
\text { length, } \\
\mathrm{cm}\end{array}$} & 4 & $6.174 \pm 0.03$ & $6.179 \pm 0.044$ & $6.236 \pm 0.038$ & $6.032 \pm 0.044$ & $6.422 \pm 0.063$ & $6.267 \pm 0.054$ & 0.000 \\
\hline & 8 & $8.879 \pm 0.039$ & $8.909 \pm 0.057$ & $8.863 \pm 0.049$ & $8.652 \pm 0.048$ & $9.123 \pm 0.083$ & $9.047 \pm 0.069$ & 0.000 \\
\hline & 12 & $10.909 \pm 0.039$ & $11.056 \pm 0.057$ & $10.911 \pm 0.05$ & $10.513 \pm 0.064$ & $11.321 \pm 0.083$ & $11.154 \pm 0.07$ & 0.000 \\
\hline \multirow{3}{*}{$\begin{array}{l}\text { Body } \\
\text { length, } \\
\mathrm{cm}\end{array}$} & 4 & $11.336 \pm 0.045$ & $11.259 \pm 0.067$ & $11.426 \pm 0.057$ & $10.797 \pm 0.024$ & $11.657 \pm 0.095$ & $11.551 \pm 0.083$ & 0.000 \\
\hline & 8 & $16.194 \pm 0.065$ & $16.227 \pm 0.096$ & $16.054 \pm 0.081$ & $15.029 \pm 0.047$ & $16.631 \pm 0.138$ & $16.416 \pm 0.116$ & 0.000 \\
\hline & 12 & $19.706 \pm 0.058$ & $19.857 \pm 0.086$ & $19.629 \pm 0.075$ & $18.272 \pm 0.002$ & $20.204 \pm 0.126$ & $19.893 \pm 0.105$ & 0.000 \\
\hline \multirow{2}{*}{$\begin{array}{l}\text { Pelvis } \\
\text { width, } \mathrm{cm}\end{array}$} & 4 & $5.101 \pm 0.025$ & $5.21 \pm 0.037$ & $5.114 \pm 0.032$ & $5.106 \pm 0.091$ & $5.282 \pm 0.053$ & $5.201 \pm 0.046$ & 0.01 \\
\hline & 8 & $6.847 \pm 0.038$ & $6.946 \pm 0.056$ & $6.764 \pm 0.048$ & $6.785 \pm 0.039$ & $7.048 \pm 0.081$ & $6.878 \pm 0.068$ & 0.037 \\
\hline
\end{tabular}

Note: ${ }^{1} P$-Value. The $P<0.01$ show the difference is very significant; The $0.01<P<0.05$ show the difference is significant

Table 3 Associations of combination haplotype with carcass traits in $\mathrm{F}_{2}$ resource population

\begin{tabular}{|c|c|c|c|c|c|c|c|}
\hline \multirow[t]{2}{*}{${ }^{1}$ Carcase Traits } & \multicolumn{6}{|l|}{ Mean \pm SE } & \multirow[t]{2}{*}{${ }^{2} P$-Value } \\
\hline & $N^{1} N^{3}$ & $N^{1} N^{4}$ & $N^{1} N^{5}$ & $N^{2} N^{3}$ & $N^{2} N^{4}$ & $N^{2} N^{5}$ & \\
\hline SEW & $1084.933 \pm 9.474$ & $1090.145 \pm 13.942$ & $1090.352 \pm 12.126$ & $918.999 \pm 13.423$ & $1188.336 \pm 20.503$ & $1131.238 \pm 17.044$ & 0.000 \\
\hline EW & $907.493 \pm 8.192$ & $909.492 \pm 12.017$ & $908.231 \pm 10.546$ & $723.094 \pm 18.074$ & $997.488 \pm 17.63$ & $949.572 \pm 14.738$ & 0.000 \\
\hline EWR & $68.081 \pm 0.117$ & $67.416 \pm 0.169$ & $68.041 \pm 0.149$ & $64.039 \pm 0.379$ & $68.548 \pm 0.252$ & $68.237 \pm 0.21$ & 0.018 \\
\hline HW & $42.804 \pm 0.3$ & $42.943 \pm 0.443$ & $43.086 \pm 0.387$ & $33.435 \pm 0.618$ & $45.083 \pm 0.65$ & $44.054 \pm 0.54$ & 0.004 \\
\hline CLW & $57.085 \pm 0.579$ & $58.911 \pm 0.857$ & $58.353 \pm 0.743$ & $47.902 \pm 0.974$ & $63.52 \pm 1.254$ & $60.246 \pm 1.034$ & 0.000 \\
\hline DWW & $121.293 \pm 1.102$ & $120.718 \pm 1.626$ & $121.298 \pm 1.414$ & $107.199 \pm 1.272$ & $131.228 \pm 2.386$ & $126.806 \pm 1.968$ & 0.000 \\
\hline PW & $3.267 \pm 0.04$ & $3.402 \pm 0.058$ & $3.365 \pm 0.051$ & $2.279 \pm 0.475$ & $3.55 \pm 0.086$ & $3.495 \pm 0.07$ & 0.002 \\
\hline BMW & $68.173 \pm 0.857$ & $68.085 \pm 1.27$ & $70.335 \pm 1.1$ & $63.975 \pm 1.285$ & $80.753 \pm 1.871$ & $74.627 \pm 1.531$ & 0.000 \\
\hline LeW & $147.192 \pm 1.379$ & $148.177 \pm 2.04$ & $147.622 \pm 1.776$ & $118.674 \pm 2.426$ & $161.028 \pm 2.98$ & $155.569 \pm 2.458$ & 0.000 \\
\hline LMW & $98.157 \pm 1.033$ & $96.924 \pm 1.532$ & $98.263 \pm 1.325$ & $80.475 \pm 1.367$ & $107.902 \pm 2.209$ & $104.103 \pm 1.822$ & 0.000 \\
\hline BMWR & $14.955 \pm 0.103$ & $14.892 \pm 0.152$ & $15.409 \pm 0.133$ & $17.748 \pm 0.23$ & $16.168 \pm 0.224$ & $15.428 \pm 0.186$ & 0.000 \\
\hline CW & $1170.048 \pm 9.697$ & $1175.501 \pm 14.284$ & $1176.849 \pm 12.424$ & $998.111 \pm 16.575$ & $1270.625 \pm 20.956$ & $1235.373 \pm 17.398$ & 0.000 \\
\hline
\end{tabular}

Note: $S E W^{1}$ semi-evisceration weight, EW evisceration weight, EWR evisceration weight ratio, $H W$ head weight, $C L W$ claw weight, $D W W$ double wings weight, $P W$ pancreas weight, $B M W$ breast muscle weight, LeW leg weight, $L M W$ leg muscle weight, $B M W R$ breast muscle weight ratio, $C W$ carcass weight

${ }^{2} P$-Value. The $P<0.01$ show the difference is very significant; The $0.01<P<0.05$ show the difference is significant

\section{Discussion}

Many studies have shown that gene polymorphisms are associated with many important economic traits in chickens. Screening for molecular markers of increased BW and muscle weight and other important economic traits is an important direction in poultry molecular breeding [29-31]. The aim of this study was to determine the effects of indels in the promoter region on growth and carcass traits and on the transcriptional activity of NUDT15 and to determine the mechanisms of the identified indel effects on growth and carcass traits in chickens. 


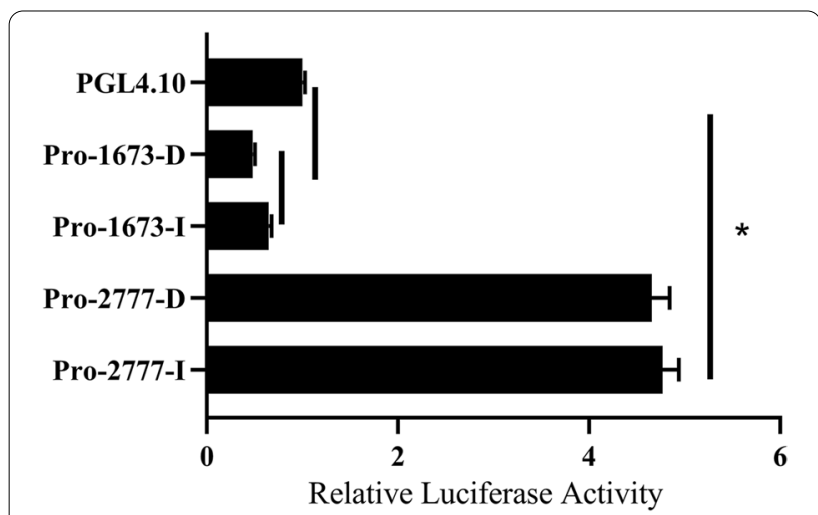

Fig. 5 The Promoter Activities of different genotypes of NUDT15 $(n=3)$. Results are expressed as the mean \pm SEM. Statistical significance of differences between means was assessed using independent sample t test. ${ }^{*} p<0.05$

Nudix hydrolase (NUDT) genes, which together comprise the NUDIX gene family, belong to a superfamily of enzymes that are conserved across all species [32, 33]. At present, 18 types of NUDIX proteins have been identified, and all family members except NUDT22 have NUDIX domains. Members of the NUDIX gene family are involved in many biological processes. One biological function in which NUDIX enzymes seem to play a role is cell cycle regulation $[34,35]$. NUDT1, NUDT5, and NUDT14 are highly expressed in cancers, indicating a potential role of these NUDIX enzymes in cancer [36]. In addition, most NUDIX proteins act on one to many substrates, which is essential for hormone-induced chromatin remodeling, transcriptional regulation, and cell proliferation [37, 38]. However, previous studies have shown that NUDT15 promotes cell proliferation by binding to PCNA and regulating DNA replication in mammalian studies [23], which is contrary to our determined role in CPMs. In comparing the amino acid series of mammals and poultry, we found great differences, and we speculate that these large differences in amino acids lead to different enzyme functions.

Allelic frequency is used to show the diversity of genes in a population arising through potential genetic drift and the introduction of novel mutations [39]. Studying the genotype distribution and allelic frequencies of gene mutations in different breeds is helpful for understanding their genetic diversity. In this study, two indels in the promoter region of NUDT15 combined to form six genotypes. $\mathrm{N}^{1} \mathrm{~N}^{4}$ was the main genotype in meat and egg hens and commercial laying hens, and the $\mathrm{N}^{1}$ allele was significantly more common than the other alleles. The proportion of commercial broilers and commercial laying hens was the highest in the $\mathrm{N}^{2} \mathrm{~N}^{5}$ genotype, and the proportions of 2777-I and 1673-D in these chickens were significantly higher than those of 2777-D and 1673-I. This may be due to the high degree of manual selection of this breed. Genotypic and allelic frequencies highly differ in different breeds, indicating that NUDT15 is highly polymorphic among different breeds. Further association analysis will be helpful for screening the dominant genotypes of NUDT15.

The results of association analysis showed that indels in the promoter region of NUDT15 could significantly affect the BW of chickens at $2 \mathrm{w}, 4 \mathrm{w}, 8 \mathrm{w}, 10 \mathrm{w}, 12 \mathrm{w}$, as well as the SC, CB, SL, and BL. The phenotypic value of the $\mathrm{N}^{2} \mathrm{~N}^{4}$ genotype was significantly higher than those of other genotypes. Previous studies have shown that chicken body shape is related to bone and muscle development. SL can reflect chicken bone and muscle development. A higher SL indicates better bone and muscle development. The growth rate of chickens is highly correlated with carcass traits, and carcass traits can relatively directly reflect the economic value of chickens. The results of the correlation analysis of carcass traits showed that SEW, EW, BMW, LMW and other key economic indicators had higher values in chickens with the $\mathrm{N}^{2} \mathrm{~N}^{4}$ genotype. In addition, the expression of NUDT15 in the leg muscle of AA broilers and LS chickens decreased gradually over time, indicating that NUDT15 may be involved in leg muscle development. This observation lays a foundation for further studies of the regulatory mechanisms of NUDT15 affecting skeletal muscle development.

Pro-1673 inhibited the expression of the NUDT15 gene, and the promoter activities of different genotypes were significantly different. The results showed that NUDT15-indel-1673 inhibited gene expression by inhibiting the activity of the NUDT15 gene promoter to different degrees. We speculate that NUDT15indel-1673 may have significant effects on the carcass and growth traits of the $\mathrm{F}_{2}$ resource population through this mechanism. Pro-2777 promoted the expression of the NUDT15 gene, but there were no significant differences in promoter activity among different NUDT15indel-2777 genotypes. NUDT15-indel-2777 may regulate differences in growth and carcass traits among different genotypes in other ways. Reducing the expression of the NUDT15 gene could promote the proliferation of CPMs, but the molecular mechanism of its inhibition is not clear. NUDT15 is highly expressed in the embryonic stage, and further analysis of the causes of the observed phenomena, the mechanisms by which NUDT15 plays different roles in mammals and poultry need to be further studied. 


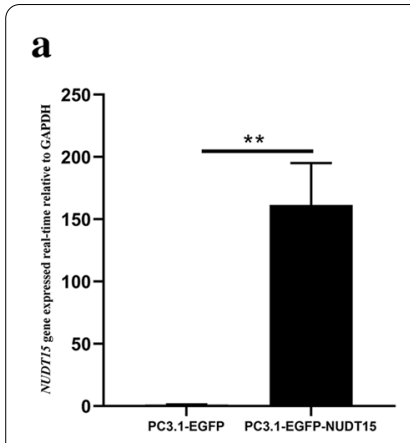

b

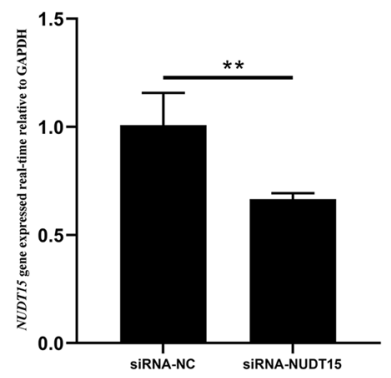

EdU
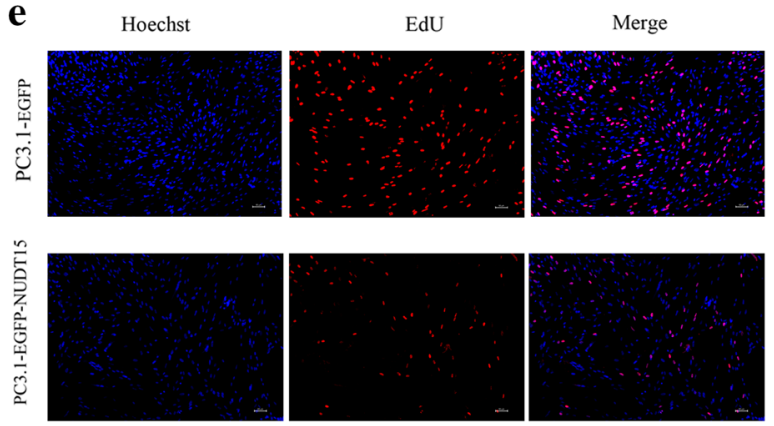

c
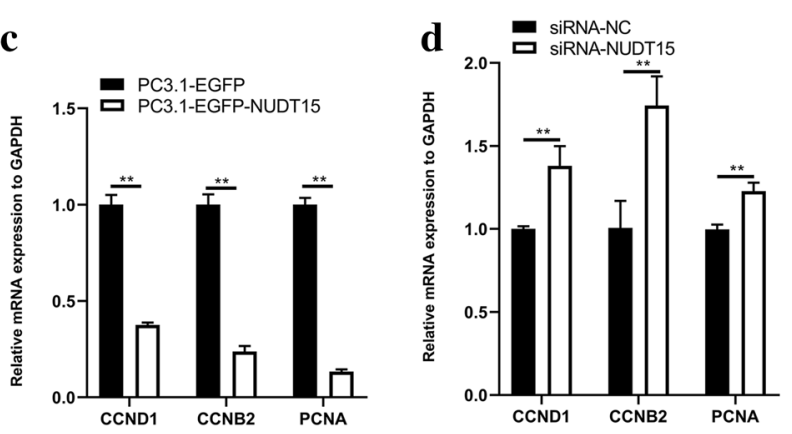

f

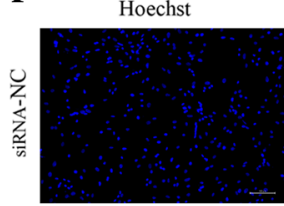

EdU
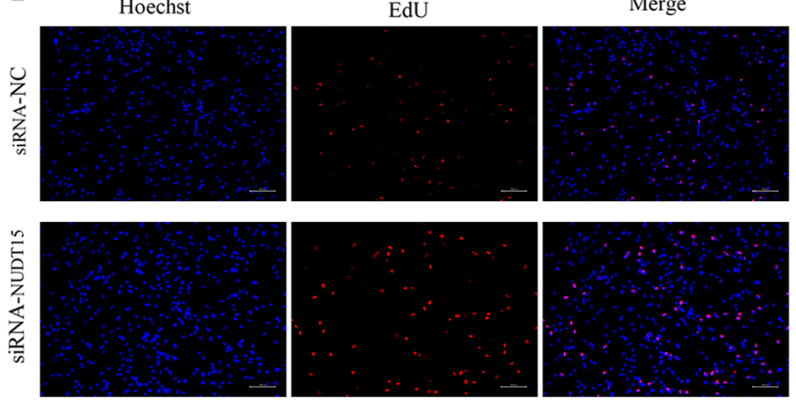

$\mathbf{k}$

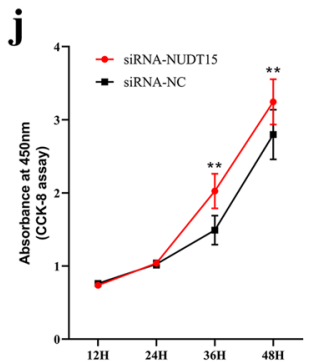

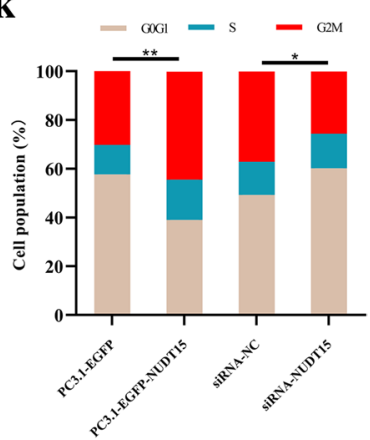

Fig. 6 The Effect of Inc9141 on Myoblast Proliferation. a-k When overexpressing or inferring with NUDT15, respectively, (a and b) mRNA expression of NUDT15 were detected $(n=6) ;(\mathbf{c}$ and $\mathbf{d})$ mRNA expression of CCND1, CCNB2, and PCNA were detected $(n=6) ;(\mathbf{e}-\mathbf{h})$ the number of proliferation cells was counted $(n=3)$; $(\mathbf{i}$ and $\mathbf{j})$ Cell growth was measured after NUDT15 overexpression or inferring $(n=8) ;(\mathbf{k})$ Cell cycle analysis of CPMs with NUDT15 overexpression or inferring $(n=3)$

\section{Conclusion}

In summary, we found two 23-bp indels in the promoter region of NUDT15. Association analysis showed that these indels could significantly affect chicken growth and carcass traits and that the $\mathrm{N}^{2} \mathrm{~N}^{4}$ genotype had the highest phenotypic value among all genotypes. The results of statistical analysis showed that the genotypic frequencies of 2777-I and 1673-D were significantly higher in commercial broilers than in other breeds. Through further study, it was found that NUDT15 could inhibit the proliferation of CPMs. The deletion allele of NUDT15-indel-1673 may inhibit the expression of NUDT15 by reducing promoter activity, thereby promoting the proliferation of CPMs to promote muscle synthesis in chickens and resulting in significantly greater phenotypic value of the $\mathrm{N}^{2} \mathrm{~N}^{4}$ genotype. In summary, these results explain the regulatory mechanisms of the effects of NUDT15-indel-1673 on several phenotypes, identify a new molecular marker that may be helpful for poultry molecular breeding, and provide a new reference for the study of molecular markers. 


\section{Materials and methods}

\section{Laboratory animals and data collection}

The animal population and experimental data used for association analyses were from the $\mathrm{F}_{2}$ resource population constructed by the Poultry Germplasm Resources Innovation Center of Henan Agricultural University [40]. Chickens were euthanized by cervical dislocation. Before euthanized, pentobarbital sodium was injected intravenously at a dose of $30 \mathrm{mg} / \mathrm{kg}$ to anesthetize the chickens.

To investigate whether this genotypic variation was present in other breeds of chickens, genomic DNA samples were obtained from 988 healthy individuals belonging to 6 dual-purpose chicken breeds Cockfighting chickens (CF, $n=87$ ), Guifei chickens (GF, $n=176$ ), Xichuan blackbone chickens (XC, $n=308$ ), Lushi green-shell layers (LS, $n=182$ ), Changshun green-eggshell chicken (CS, $n=92$ ), and Gushi chickens (GS, $n=143)$ ). In addition, commercial laying hens, namely, Hy-Line (HL, $n=222$ ), and commercial broilers, namely, the Hubbard broiler (HBD, $n=236$ ) and Arbor Acres (AA, $n=309$ ), were also tested to verify the prevalence of these mutations in different breeds.

\section{Genomic DNA extraction and PCR}

A DNA extraction kit was used to extract genomic DNA from blood samples, and the quality of the obtained genomic DNA was determined. The primer pairs used in this study are listed in Table 4. All primers were designed using the online primer design tool Primer-BLAST (http:// www.ncbi.nlm.nih.gov/tools/primer-blast/) and synthesized by Sangon Biotech Company (Shanghai, China). The NUDT15 primers were used to identify and genotype the indels in the NUDT15. PCR was performed in $10 \mu \mathrm{l}$ reactions containing $50 \mathrm{ng}$ of DNA, $0.3 \mu \mathrm{M}$ of each primer, $5 \mu \mathrm{l}$ of $2 \times$ Taq Master Mix (Q711, Vazyme Biotech Co., Ltd) and $3 \mu \mathrm{l}$ of double-distilled water. The cycle parameters were as follows: $95^{\circ} \mathrm{C}$ for $5 \mathrm{~min}$; 35 cycles of $95^{\circ} \mathrm{C}$ for $10 \mathrm{~s}$, $61^{\circ} \mathrm{C}$ for $10 \mathrm{~s}$, and $72^{\circ} \mathrm{C}$ for $15 \mathrm{~s}$; and finally an additional 5 -min extension at $72^{\circ} \mathrm{C}$. The PCR products were separated by electrophoresis on a $2.5 \%$ agarose gel stained with DNAGREEN in $1 \mathrm{X}$ TAE buffer. The differences in the frequencies among the populations were analyzed according to the $\chi^{2}$ test using SPSS 22.0 (Chicago, IL, USA).

\section{Sample collection, RNA extraction, cDNA synthesis, and qPCR methods}

The leg and breast muscle were collected from AA and LS chickens at E10, E12, E14, E16, E18, 1D, $1 \mathrm{~W}, 3 \mathrm{~W}$, and $5 \mathrm{~W}$. The leg muscle, breast muscle, heart, liver, and muscular stomach of AA at E12 and the leg muscle, breast muscle, heart, liver, pancreas, spleen, kidney, abdominal fat, and duodenum of AA at $2 \mathrm{~W}$ were also collected. Total RNA was extracted using RNA isolater Total RNA Extraction
Table 4 Details of primer pairs for the chicken NUDT15 gene

\begin{tabular}{|c|c|c|c|}
\hline Primer set & Primer sequence, $5^{\prime}-3^{\prime}$ & $\mathrm{Tm},{ }^{\circ} \mathrm{C}$ & $\begin{array}{l}\text { Product } \\
\text { size, bp }\end{array}$ \\
\hline NUDT15-indel-2777-F & $\begin{array}{l}\text { TGTGAGCTACACAGCTAG } \\
\text { AACT }\end{array}$ & 61 & 113 \\
\hline NUDT15- indel-2777-R & ATTGGAGGGCTTGGCAATCA & & \\
\hline NUDT15- indel-1673-F & $\begin{array}{l}\text { ACAGGAGCACATAAATCA } \\
\text { TAGCCT }\end{array}$ & 62 & 150 \\
\hline NUDT15- indel-1673-R & $\begin{array}{l}\text { TGGCCAGTATTTTTAAAGTGTG } \\
\text { ATGA }\end{array}$ & & \\
\hline qPCR-NUDT15-F & ACCTGGAGTTCGGGGAGAG & 60 & 145 \\
\hline qPCR-NUDT15-R & ATGAGCACGGTGACGTAGTG & & \\
\hline GAPDH-F & GAACATCATCCCAGCGTCCA & $55-65$ & 132 \\
\hline GAPDH-R & CGGCAGGTCAGGTCAACAAC & & \\
\hline CCND1 -F & CAGAAGTGCGAAGAGGAAGT & 59 & 188 \\
\hline CCND1 - R & CTGATGGAGTTGTCGGTGTA & & \\
\hline CCNB2-F & ССТСТTCCACTTCACTTCT & 59 & 195 \\
\hline CCNB2-R & СTTTGTACCCCACTTATCA & & \\
\hline PCNA-F & AGCACCAAATCAGGAAAAG & 59 & 177 \\
\hline PCNA-R & GCACAGGAGATGACAACAG & & \\
\hline
\end{tabular}

Reagent (R401-1, Vazyme Biotech Co., Ltd) as recommended by the supplier. cDNA synthesis for mRNA was carried out using the HiScript III RT SuperMix for qPCR (+gDNA wiper) (R323-01, Vazyme Biotech Co., Ltd). qPCR was performed on an ABI 7500 instrument (Applied Biosystems) using SYBR Green qPCR Mix (Q711, Vazyme Biotech Co., Ltd) according to the manufacturer's protocol in a two-step method. For each $10 \mu \mathrm{L}$ reaction, $0.4 \mu \mathrm{L}$ of $10 \mu \mathrm{M}$ primer mix and $25 \mathrm{ng}$ of cDNA were added, and $2^{-\Delta \Delta \mathrm{Ct}}$ analyses were performed as described previously. Chicken GAPDH was used as an internal control. The primer sequences for all PCRs performed are listed in Table 4.

\section{Statistical analysis}

The growth and carcass traits of the $F_{2}$ population were analyzed by SPSS software (SPSS for Windows, standard version 24.0; SPSS, USA). Two models were used for analysis. Model I was used to evaluate growth traits, and model II considered CW as an adjoint variable. The models were as follows:

$$
\begin{aligned}
& \text { Model I: } Y_{i j k l m}=\mu+G_{i}+S_{j}+H_{k}+f_{l}+e_{i j k l m} \\
& \text { Model II: } Y_{i j k l m}=\mu+G_{i}+S_{j}+H_{k}+f_{1}+b\left(W_{i j k l m}-W\right)+e_{i j k l m}
\end{aligned}
$$

where $Y_{i j k l m}$ represents the observed value; $\mu$ is the overall population mean; $G_{i}$ represents the fixed effect of the genotype; $S_{j}$ represents the fixed effect of sex; $\mathrm{H}_{k}$ represents the fixed effect of the hatch; $f_{1}$ is the fixed effect of the family; $\mathrm{e}_{\mathrm{ijklm}}$ is the random error; $\mathrm{b}$ is the regression 
coefficient for $\mathrm{CW} ; \mathrm{W}_{\mathrm{ij} k \mathrm{~km}}$ represents the individual slaughter weight; and $\overline{\mathrm{W}}$ is the average slaughter weight. A $p$-value $<0.05$ was considered statistically significant, and the influence of the genotypes of the studied polymorphisms on the target traits was investigated by least squares analysis. Bonferroni's test was used to control for multiple comparisons [41, 42].

\section{Vector construction}

Full-length NUDT15 constructs were cloned into vectors to generate expression plasmids. NUDT15 was cloned into pcDNA3.1 using HindIII/EcoRI. NUDT15 promoter deletion constructs were cloned into pGL4.10 using KpnI/SacI. A ClonExpress II One Step Cloning Kit (C112-02, Vazyme Biotech Co., Ltd) was used to ligate the cloned fragments into each vector.

\section{Cell culture, transfection, and treatment}

DF1 cells were cultured in F12 DMEM (BI) supplemented with $10 \%$ FBS (BI) and 1\% penicillin/streptomycin (Solarbio).

CPMs were isolated from the leg muscles of embryonic day 11 (E11) individuals as previously described [43]. The obtained cells were cultured in high-glucose DMEM (Biological Industries,Israel) supplemented with 15\% FBS (Biological Industries,Israel) and 1\% penicillin/streptomycin (Solarbio). For CPM differentiation, CPMs were transferred into differentiation medium supplemented with $2 \%$ horse serum when the cells had reached $>90 \%$ confluence. Cells were incubated at $37{ }^{\circ} \mathrm{C}$ in an atmosphere of $5 \% \mathrm{CO}_{2}$.

PGL-4.10 and PCDNA3.1-EGFP were transfected using Lipofectamine 3000 (Invitrogen) according to the manufacturer's protocol into cells at $80 \%$ confluence. siRNA-NUDT15 was transfected using Lipofectamine RNAiMAX (Invitrogen) according to the manufacturer's protocol into cells at $40 \%$ confluence.

\section{Dual fluorescence detection}

DF1 cells were cultured in 24-well plates. When the cells reached $80 \%$ confluence, they were cotransfected with different recombinant plasmids or the internal reference plasmid (pRL-TK). The total amount of transfected DNA per well was $880 \mathrm{ng}$, and The transfection ratio of pGL4.10-Pro and the internal reference vector (pRL-TK) was 10:1. Three biological replicates were performed for each treatment. After $36 \mathrm{~h}$, the transfected cells were lysed in $100 \mu \mathrm{L}$ of $1 \times$ passive lysis buffer (PLB) (Promega) at room temperature for $30 \mathrm{~min}$. Dual luciferase activity was measured, and firefly luciferase activity was normalized to Renilla luciferase activity (pRL-TK).

\section{Flow cytometry, EdU, and CCK-8 assays}

For flow cytometry analysis of the cell cycle, myoblasts were seeded in 12-well plates. After a 36-h transfection, cells cultured in growth media were collected and fixed overnight in $75 \%$ ethanol at $4{ }^{\circ} \mathrm{C}$. The cells were analyzed with a cell cycle analysis kit (KGA512, KeyGEN BioTECH) on a BD Accuri C6 flow cytometer (BD Biosciences), and the data were processed using FlowJo software (7.6, Tree Star, Ashland, OR, USA).

For the EdU assay, CPMs were seeded in 24-well plates, cultured to $40 \%$ density (siRNA) or $70 \%$ density (PCDNA3.1-EGFP) and then transfected. Thirty-six hours after transfection, the cells were fixed and stained with an EdU Apollo in vitro imaging kit (C10310, RiboBio) as previously described. A fluorescence microscope (SONY) was used to capture three randomly selected fields, and the number of EdU-stained cells in the fields was determined.

For the CCK-8 assay, CPMs were seeded in a 96-well plate and cultured in growth medium. After transfection, the proliferation of the cell culture at 12, 24, 36, and $48 \mathrm{~h}$ was monitored using the CCK8 kit (A311-01, Vazyme Biotech Co., Ltd) according to the manufacturer's protocol. The absorbance data at $450 \mathrm{~nm}$ were read by an iMark microplate absorbance reader (Bio-Rad). All of the data were acquired by averaging the results of six independent replicates.

\section{Supplementary Information}

The online version contains supplementary material available at https://doi. org/10.1186/s12864-022-08362-6.

Additional file 1.

Acknowledgements

Not applicable.

Authors' contributions

C.W. and Y. N. designed analysis, performed analysis and wrote manuscript; B.C., P.Q., Y.W., D.H., T.L., R.L., and C.W. performed the wet-lab experiment; R.H., H.X., Y.T., X.L., X.K. contributed to sample collection and construction of $F_{2}$ resource population. H. Y. and Z.L. assisted with data analysis and manuscript revision. C.W. and Z. L. conceived research designed analysis and revised manuscript. The author(s) read and approved the final manuscript.

\section{Funding}

This work was supported by the grants from the National Natural Science Foundation of China-Henan joint grant (U1804107), the Zhongyuan Youth Talent Support Program (ZYYCYU202012156), and the Key Science and Technology Research Project of Henan Province (202102110085). We are grateful to the editor and reviewers for their comments and suggestions.

\section{Availability of data and materials}

The raw sequence data of NUDT15-indel-2777 and NUDT15-indel-1673 have been deposited at the European Variation Archive (EVA) under Project identified PRJEB47912. 


\section{Declarations}

\section{Ethics approval and consent to participate}

The experiments and animal care were performed according to the Regulations for the Administration of Affairs Concerning Experimental Animals (Ministry of Science and Technology, China, 2004). The protocols were approved by the Institutional Animal Care and Use Committee of Henan Agricultural University, China. In this study, written informed consent was obtained from Henan Agricultural University to use these animals. The study was carried out in compliance with the ARRIVE guidelines.

\section{Consent for publication}

Not applicable.

\section{Competing interests}

The authors declare that they have no competing interests.

\section{Author details}

${ }^{1}$ College of Animal Science and Technology, Henan Agricultural University, Zhengzhou 450046, China. ${ }^{2}$ Henan Key laboratory for innovation and utilization of chicken germplasm resources, Zhengzhou 450046, China. ${ }^{3}$ Farm Animal genetic resources exploration and innovation key laboratory of sichuan province, sichuan agricultural university, Chengdu, China.

Received: 18 October 2021 Accepted: 25 January 2022

Published online: 16 February 2022

\section{References}

1. Imsland F, Feng C, Boije H, et al. The rose-comb mutation in chickens constitutes a structural rearrangement causing both altered comb morphology and defective sperm motility. PLoS Genet. 2012;8(6):e1002775. https://doi.org/10.1371/journal.pgen.1002775.

2. Zhang Y, Wang Y, Li Y, et al. Genome-wide association study reveals the genetic determinism of growth traits in a Gushi-Anka $\mathrm{F}_{2}$ chicken population. Heredity. 2021;126(2):293-307. https://doi.org/10.1038/ s41437-020-00365-X.

3. Li W, Jing Z, Cheng Y, et al. Analysis of four complete linkage sequence variants within a novel IncRNA located in a growth QTL on chromosome 1 related to growth traits in chickens. J Anim Sci. 2020;98(5):skaa122. https://doi.org/10.1093/jas/skaa122.

4. Win TK, Yamagata Y, Doi K, et al. A single base change explains the independent origin of and selection for the nonshattering gene in african rice domestication. New Phytol. 2017;213(4):1925-35. https:// doi.org/10.1111/nph.14290.

5. Wang Y, Cao X, Luo C, et al. Multiple ancestral haplotypes harboring regulatory mutations cumulatively contribute to a QTL affecting chicken growth traits. Commun Biol. 2020;3(1):472. https://doi.org/10. 1038/s42003-020-01199-3.

6. Jia X, Lin H, Nie Q, Zhang X, Lamont SJ, et al. A short insertion mutation disrupts genesis of mir-16 and causes increased body weight in domesticated chicken. Sci Rep. 2016;6:36433. https://doi.org/10.1038/ srep36433.

7. Xie L, Luo C, Zhang C, et al. Genome-wide association study identified a narrow chromosome 1 region associated with chicken growth traits. PLoS One. 2012;7(2):e30910. https://doi.org/10.1371/journal.pone. 0030910.

8. Uemoto $Y$, Sato $S$, Odawara $S$, et al. Genetic mapping of quantitative trait loci affecting growth and carcass traits in $\mathrm{F}_{2}$ intercross chickens. Poult Sci. 2009:88(3):477-82. https://doi.org/10.3382/ps.2008-00296.

9. Podisi BK, Knott SA, Burt DW, et al. Comparative analysis of quantitative trait loci for body weight, growth rate and growth curve parameters from 3 to 72 weeks of age in female chickens of a broilerlayer cross. BMC Genet. 2013;14(1):1-11. https://doi.org/10.1186/ 1471-2156-14-22

10. Liu DL, Wang XL, Li WY, et al. A novel 86-bp indel of the motilin receptor gene is significantly associated with growth and carcass traits in Gushi-Anka F $F_{2}$ reciprocal cross chickens. Br Poult Sci. 2019;60(6):64958. https://doi.org/10.1080/00071668.2019.1655710.
11. Zhang H, Liu SH, Zhang $Q$, et al. Fine-mapping of quantitative trait loci for body weight and bone traits and positional cloning of the RB1 gene in chicken. J Anim Breed Genet. 2011;128(5):366-75. https://doi. org/10.1111/j.1439-0388.2011.00927.x.

12. Jia $X$, Ouyang $H$, Abdalla BA, et al. Mir-16 controls myoblast proliferation and apoptosis through directly suppressing BCL2 and FOXO1 activities. Biochim Biophys Acta. 2017;1860(6):674-84. https://doi.org/ 10.1016/j.bbagrm.2017.02.010.

13. Handsaker RE, Doren VV, Berman JR, et al. Large multiallelic copy number variations in humans. Nat Genet. 2015;47(3):296-303. https://doi. org/10.1038/ng.3200.

14. Manel S, Guerin PE, Mouillot D, et al. Global determinants of freshwater and marine fish genetic diversity. Nature. Communications. 2020;11(1):692. https://doi.org/10.1038/s41467-020-14409-7.

15. Campbell IM, Gambin T, Jhangiani SN, et al. Multiallelic positions in the human genome: challenges for genetic analyses. Hum Mutat. 2015;37(3):231-4. https://doi.org/10.1002/humu.22944.

16. Matteo C, Johansson KE, Audrone V, et al. Understanding the origins of loss of protein function by analyzing the effects of thousands of variants on activity and abundance. Mol Biol Evol. 2021;38(8):3235-46. https://doi.org/10.1093/molbev/msab095.

17. Walker GJ, Harrison JW, Heap GA, et al. Association of genetic variants in NUDT15 with thiopurine-induced myelosuppression in patients with inflammatory bowel disease. JAMA. 2019;321(8):773-85. https://doi. org/10.1001/jama.2019.0709.

18. Moriyama T, Nishii R, Perez-Andreu V, et al. NUDT15 polymorphisms alter thiopurine metabolism and hematopoietic toxicity. Nat Genet. 2016;48(4):367-73. https://doi.org/10.1038/ng.3508.

19. Karran P, Attard N. Thiopurines in current medical practice: molecular mechanisms and contributions to therapy-related cancer. Nat Rev Cancer. 2008:8(1):24-36. https://doi.org/10.1038/nrc2292.

20. Yang SK, Hong M, Baek J, Choi H, Zhao W, Jung Y, et al. A common missense variant in nudt 15 confers susceptibility to thiopurine-induced leukopenia. Nat Genet. 2014;46(9):1017-20. https://doi.org/10.1038/ng 3060.

21. Yang JJ, Landier $W$, Yang $W$, et al. Inherited nudt 15 variant is a genetic determinant of mercaptopurine intolerance in children with acute lymphoblastic leukemia. J Clin Oncol. 2015;33(11):1235-42. https://doi. org/10.1200/jco.2014.59.4671.

22. Si MJ, Matthieu D, Anna H, et al. Development of a chemical probe against NUDT15. Nat Chem Biol. 2020;16(10):1120-8. https://doi.org/10. 1038/s41589-020-0592-z.

23. Yu Y, Cai JP, Tu B, et al. Proliferating cell nuclear antigen is protected from degradation by forming a complex with MutT Homolog2. J Biol Chem. 2009;284(29):19310-20. https://doi.org/10.1074/jbc.m109.015289.

24. Haberle V. Stark, Alexander eukaryotic core promoters and the functional basis of transcription initiation. Nat Rev Mol Cell Biol. 2018;19(10):621-37. https://doi.org/10.1038/s41580-018-0028-8.

25. Blazeck J, Garg R, Reed B, et al. Controlling promoter strength and regulation in Saccharomyces cerevisiae using synthetic hybrid promoters. Biotechnol Bioeng. 2012;109(11):2884-95. https://doi.org/10.1002/bit. 24552.

26. Gacita AM, Dellefave-Castillo LP, P, Barefield DY, Mcnally E M. Altered enhancer and promoter usage leads to differential gene expression in the normal and failed human heart. Circulation. Heart Failure. 2020;13(10). https://doi.org/10.1161/circheartfailure.120.006926.

27. Jie $Y E, W a n g X, X u H T$, et al. An indel in the promoter of al-activated malate transporter9 selected during tomato domestication determines fruit malate contents and aluminum tolerance. Plant Cell. 2017;29(9):2249. https://doi.org/10.1105/tpc.17.00211.

28. XUY, Shi T, Zhou Y, et al. A novel PAX7 10-bp indel variant modulates promoter activity, gene expression and contributes to different phenotypes of chinese cattle. Sci Rep. 2018;8(1):1724. https://doi.org/10.1038/ s41598-018-20177-8.

29. Wang $X$, Wang $X$, Chen B, et al. Association of a new 99-bp indel of the cel gene promoter region with phenotypic traits in chickens. Sci Rep. 2020;10(1):3215. https://doi.org/10.1038/s41598-020-60168-2.

30. Wang $\mathrm{K}, \mathrm{Hu} \mathrm{H}$, Tian $\mathrm{Y}$, et al. The chicken pan-genome reveals gene content variation and a promoter region deletion in IGF2BP1 affecting body size. Mol Biol Evol. 2021;msab231. https://doi.org/10.1093/molbev/msab2 31. 
31. Fang MX, Nie QH, Luo CL, de Zhang X, Zhang XQ. Associations of GHSR gene polymorphisms with chicken growth and carcass traits. Mol Biol Rep. 2010;37:423-8. https://doi.org/10.1007/s11033-009-9556-9.

32. Bessman MJ, Frick DN, O'Handley SF. The MUTT proteins or "Nudix" hydrolases, a family of versatile, widely distributed, "housecleaning" enzymes. J Biol Chem. 1996;271:25059-62. https://doi.org/10.1074/jbc.271.41.25059.

33. McLennan AG. The MutT motif family of nucleotide phosphohydrolases in man and human pathogens (review) Int. J Mol Med. 1999;4(1):79-89. https://doi.org/10.3892/ijmm.4.1.79.

34. Abolhassani N, lyama T, Tsuchimoto D, et al. NUDT16 and ITPA play a dual protective role in maintaining chromosome stability and cell growth by eliminating dIDP/IDP and dITP/ITP from nucleotide pools in mammals. Nucleic Acids Res. 2010;38:2891-903. https://doi.org/10.1093/nar/gkp12 50.

35. Baguma-Nibasheka M, Li AW, Murphy PR. The fibroblast growth factor-2 antisense gene inhibits nuclear accumulation of FGF-2 and delays cell cycle progression in C6 glioma cells. Mol Cell Endocrinol. 2007;267:12736. https://doi.org/10.1016/j.mce.2007.01.008.

36. Gad H, Koolmeister T, Jemth A-S, et al. MTH1 inhibition eradicates cancer by preventing sanitation of the dNTP pool. Nature. 2014;508:215-21. https://doi.org/10.1038/nature13181.

37. Carreras-Puigvert J, Zitnik M, Jemth AS, et al. A comprehensive structural, biochemical and biological profiling of the human NUDIX hydrolase family. Nat Commun. 2017;8(1):1541. https://doi.org/10.1038/ s41467-017-01642-w.

38. Wright RH, Lioutas A, Le Dily F, et al. ADP-ribose-derived nuclear ATP synthesis by NUDIX5 is required for chromatin remodeling. Science. 2016;352(6290):1221-5. https://doi.org/10.1126/science.aad9335.

39. Väli U, Brandström M, Johansson M, Ellegren H. Insertion-deletion polymorphisms (indels) as genetic markers in natural populations. BMC Genet. 2008:9:8. https://doi.org/10.1186/1471-2156-9-8.

40. Han RL, Li ZJ, Li MJ, et al. Novel 9-bp indel in visfatin gene and its associations with chicken growth. Br Poult Sci. 2011;52(1):52-7. https://doi.org/ 10.1080/00071668.2010.537310.

41. LiW, Liu D, Tang S, et al. A multiallelic indel in the promoter region of the Cyclin-dependent kinase inhibitor 3 gene is significantly associated with body weight and carcass traits in chickens. Poult Sci. 2019;98(2):556-65. https://doi.org/10.3382/ps/pey404.

42. Jing ZZ, Wang XL, Cui YY, et al. Detection of CNV in the SH3RF2 gene and its effects on growth and carcass traits in chickens. BMC Genet. 2020;21(1):22. https://doi.org/10.1186/s12863-020-0831-z.

43. Cai B, Ma M, Chen B, Li Z, Abdalla BA, et al. Mir-16-5p targets SESN1 to regulate the P53 signaling pathway, affecting myoblast proliferation and apoptosis, and is involved in myoblast differentiation. Cell Death Dis. 2018;9(3):367. https://doi.org/10.1038/s41419-018-0403-6.

44. Ren T, LiW, Liu D, et al. Two insertion/deletion variants in the promoter region of the QPCTL gene are significantly associated with body weight and carcass traits in chickens. Anim Genet. 2019;50(3):279-82. https://doi. org/10.1111/age.12741.

45. Wang Z, Qu L, Yao J, et al. An EAV-HP insertion in $5^{\prime}$ flanking region of SLCO1B3 causes blue eggshell in the chicken. PLoS Genet. 2013;9(1):e1003183. https://doi.org/10.1371/journal.pgen.1003183.

\section{Publisher's Note}

Springer Nature remains neutral with regard to jurisdictional claims in published maps and institutional affiliations.

Ready to submit your research? Choose BMC and benefit from:

- fast, convenient online submission

- thorough peer review by experienced researchers in your field

- rapid publication on acceptance

- support for research data, including large and complex data types

- gold Open Access which fosters wider collaboration and increased citations

- maximum visibility for your research: over $100 \mathrm{M}$ website views per year

At BMC, research is always in progress.

Learn more biomedcentral.com/submissions 